22

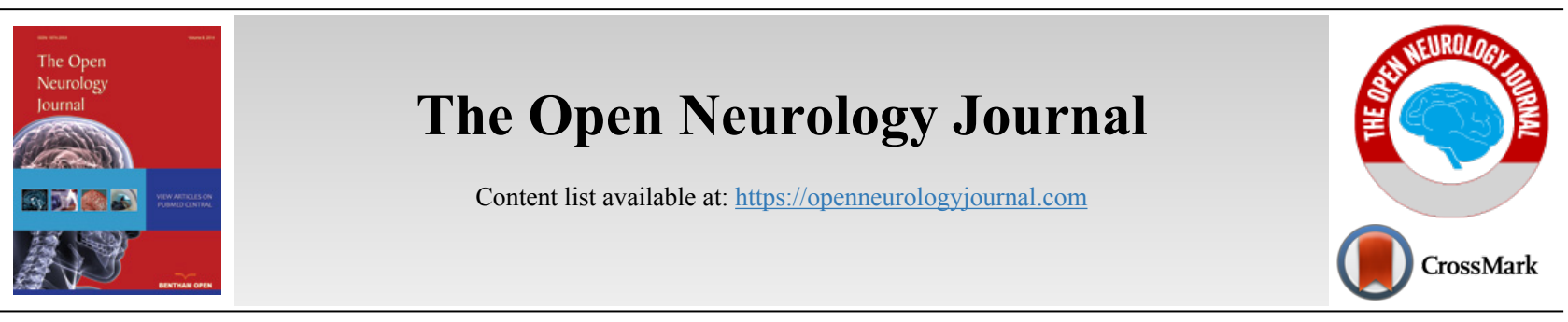

REVIEW ARTICLE

\title{
Psychopharmacological Options in the Multidisciplinary and Multidimensional Treatment of Eating Disorders
}

\author{
Walter Milano $^{1}$ and Anna Capasso, ${ }^{2, *}$ \\ ${ }^{1}$ Departmental Operative Unit, "EatingDisorders" ASL North Naples 2, Italy \\ ${ }^{2}$ Department of Pharmacy, University of Salerno, 84084-Fisciano, Italy
}

\begin{abstract}
Eating Disorders (ED) are a syndrome characterized by persistent alteration of eating behavior and the conditions that cause insufficient ingestion and/or adsorption of foods. There are three different ED diseases: Anorexia Nervosa (AN), Bulimia Nervosa (BN) and Binge Eating Disorders (BED). ED are complex conditions that arise from a combination of long-standing behavioral, emotional, psychological, interpersonal, and social factors. A common trait to all EDs is the incongruous diet, often based on arbitrary parameters, disconnected from physiological needs, with a strong alteration of the sensations of hunger and satiety, to which variations in weight, body composition, health status and quality of life of patients occur. Although EDs are relatively frequent psychiatric disorders in the general population, especially in adolescent and juvenile age groups, evidence based on the scientific evidence of the efficacy of the pharmacological treatment of EDAs remains modest. The currently available international guidelines related to the pharmacological treatment of EDs are currently few and not always adequately informative, as they are affected by the lack of studies on the subject. As a further consequence of this it is not surprising that, with the sole exception of fluoxetine for the treatment of Bulimia Nervosa $(\mathrm{BN})$ symptoms, no psychopharmaceutical has been authorized by national and international regulators for the treatment of ED.

This narrative review focuses on the advantages and limitations of drugs used in the treatment of ED.
\end{abstract}

Keywords: Antidepressants, Anti-obesity drugs, Antipsychotics, Eating Disorders, Hormonal therapy, Mood stabilizing drugs.

\begin{tabular}{|c|c|c|}
\hline Article History & Received: January 04, 2019 & Revised: February 02, 2019 \\
\hline
\end{tabular}

\section{INTRODUCTION}

Eating disorders (ED) are diseases with a high social impact, which mainly affect the younger sections of the population. Their clinical performance is characterized by frequent exacerbations and/or relapses, a tendency towards chronicity, significant medical sequelae and psychiatric comorbidity; this makes these pathologies one of the most serious and disabling in the psychiatric field, also considering the significant risk of associated mortality [1]. The clinical complexity of ED corresponds to the need to articulate necessarily multidimensional therapeutic projects, which are based on a wide range of skills and interventions that include at least nutritional rehabilitation, management of medical complications, psychotherapies and pharmacological treatment.

In particular, pharmacotherapy has so far proved more useful in the treatment of medical complications, malnutrition deficits and psychiatric comorbidities (extremely frequent in this type of pathology), than in inducing a real control of the

\footnotetext{
* Address correspondence to this author at the Department of Pharmacy, University of Salerno, 84084-Fisciano, Italy; E-mail: annacap@unisa.it
}

core symptoms of ED. Basically, all the main classes of pharmacological agents have been used in clinical practice in an attempt to treat the clinical manifestations of ED, but the results from randomized controlled studies on the subject are still contradictory [2].

Although EDs are relatively frequent psychiatric disorders in the general population, especially in adolescent and juvenile age groups, evidence based on the scientific evidence of the efficacy of the pharmacological treatment of EDs remains modest. The currently available international guidelines relating to the pharmacological treatment of EDs are currently few [3 - 5] and not always adequately informative, as they are affected by the lack of studies on the subject. As a further conse-quence of this, it is not surprising that with the sole exception of fluoxetine for the treatment of Bulimia Nervosa (BN) symptoms and of lisdexamfetamine for the Binge Eating Disorder (BED), no psychopharmaceutical has been authorized by national and international regulators for the treatment of ED. The main available evidence concerning the pharmacotherapy of ED will be summarized below for each of the main classes of pharmacological agents active on the central nervous system. 
The purpose of this review is to summarize all the various possible psychopharmacological options in the multidisciplinary and multidimensional treatment in ED.

\section{ADVANTAGES AND LIMITATIONS OF DRUGS USED IN THE TREATMENT OF ED}

\subsection{Antipsychotics}

Antipsychotic Drugs (AP) are often used, albeit with some caution, in the treatment of anorexia nervosa (AN). The pharmacodynamic action of AP is mainly focused on the modulation of dopaminergic and serotonergic systems, which can induce an increase in appetite and therefore a weight increase. Numerous evidence has shown that subjects with severe mental disorders, such as schizophrenia or bipolar disorder, who are treated with AP drugs, tend to gain weight in a considerable percentage of cases [6]. Paradoxically, in the AN, the APs have not proved to be particularly useful for inducing weight recovery but states are rather used to treat other syndromic features characteristic of this disorder such as the distortion of the body image, the ideation pathologically focused on weight and food, the fear of getting fat, obsessive ideation, bodily misuse, hyper-arousal and psychomotor agitation [7].

Already in the early ' 80 s, Vandereycken and collaborators $[8,9]$ had produced the first controlled evidence concerning the use of first-generation AP drugs (First Generation Antipsychotics, FGA) for EDs, albeit on rather small samples. For both pimozide [8] and sulpiride [9], initial weight gain, after a threemonth clinical observation period, was not significantly higher than the placebo effect. In the early 2000 s, with the introduction of second-generation antipsychotics (Second-Generation Antipsychotics, SGA), some promising studies on the treatment of AN were published in the literature, especially with olanzapine, a D2/5HT2 receptor antagonist. Mondraty et al. [10] reported higher efficacy of olanzapine $(10 \mathrm{mg} /$ day $)$ compared to chlorpromazine $(50 \mathrm{mg} /$ day $)$, in reducing the obsessive rumination of patients with AN. Brambilla et al. [11] comparing the effects of treatment with low doses of olanzapine $(2.5 \mathrm{mg} /$ day in the first month and then $5 \mathrm{mg} /$ day for two months) compared to placebo, in 30 anorexic patients who also performed a cycle of cognitive-behavioral psychotherapy (Cognitive-Behavioral Therapy, CBT) in out-patient settings, reported greater weight gain and a significant reduction of depressive symptoms and aggression in the olanzapine-treated group. Bissada et al. [12] compared the efficacy of olanzapine vs placebo, over a period of 10 weeks, in a sample of 34 patients with $\mathrm{AN}$; the group treated with olanzapine had a significantly higher rate of weight gain and improvement of the obsessive symptoms, measured with the Yale Brown Obsessive-Compulsive Rating Scale.

Other SGAs, such as risperidone, quetiapine, and ziprasidone have not been investigated by Randomized Clinical Trials (RCTs) for the treatment of AN [13]. The few RTCs currently available in the literature on the subject suggest a possible role of EMSs in reducing the psychiatric symptoms associated with AN and in promoting weight recovery.

A few case reports suggest that aripiprazole a partial dopamine agonist may also be effective in the treatment of AN
[14]. In a chart review of 75 patients with AN who recei-ved either olanzapine or aripiprazole, aripiprazole showed the greatest effectiveness in reducing eating-related preoccupations and rituals with a large effect size [15]. In the literature, relatively small doses were used, in a case series published by Trunko et al., patients received aripiprazole doses of between 5 and $15 \mathrm{mg} / \mathrm{die}$ [16].

For example, Hagman et al. [17] verified the effect of risperidone $(2.5 \mathrm{mg} /$ day $)$ in a group of 40 young women or adolescents with AN, compared to placebo, reporting an initial improvement in the indices related to food psychopathology, which however was not significantly higher than the end of the observation period; in addition, patients treated with risperidone had higher levels of prolactin and reported experiences of intrusiveness and coercivity. The possible side effects of such drugs (eg extrapyramidal manifestations, cardiac complications such as QTc elongation, hyperprolactinemia and hypoestrogenism, with reduced bone density) make it risky to use in frail, underweight patients and with frequently associated electrolyte imbalances, such as those with AN. It is not surprising, therefore, that to date, the main international guidelines [3 - 5] consider the use of EMSs as a substantially secondary therapeutic alternative for the AN.

There are no randomized controlled trials on the use of antipsychotics in the treatment of Bulimia Nervosa (BN) and Binge Eating Disorder (BED); on the contrary, different evidence seems to suggest that EMS may even induce or exacerbate binge eating crises in patients with DCA, as well as in psychotic patients [18].

\subsection{Antidepressants}

The use of Antidepressant Drugs (AD) in the treatment of ED appears plausible not only in relation to the high rates of comorbidity of ED with mood disorders (even above 50\%) [19], but also for the scientific evidence that they tend to demonstrate the involvement of serotonergic and noradrenergic neurotransmitter systems in the genesis of ED.

Numerous molecules with antidepressive action act as enhancers of the serotonergic system, which is significantly involved with modulation activities of numerous and relevant clinical and pathogenic aspects of ED; some manifestations typical of eating disorders such as the alteration of the sense of hunger and satiety, impulsivity, obsessiveness, aggression or anxiety, have been related to a functional hypotonous of the serotonergic system [20].

However, the role of EDs, both the so-called "tricyclics" (tryciclic antidepressants, TCA) and the more recent selective serotonin reuptake inhibitors (Selective Serotonine Reuptake Inhibitors, SSRIs) in inducing weight gain in patients with AN still appears today not significant. A systematic review of the data from the literature on the efficacy of $\mathrm{AD}$ in the treatment of the acute phase of the AN [20] revealed the presence of only four RCT studies on the subject, three of which were conducted with TCA (amitriplina and clomipramine) and one with SSRI (fluoxetine); none of the RCTs examined reported significant clinical and/or body weight gains compared to the control group, while they detected greater potential cardiovascular risks for tricyclic drugs. 
A possible explanation for the rather unsatisfactory results obtained by the serotonergic drugs in the acute phase of the AN can be related to the reduced intake of tryptophan, amino acid precursor of serotonin: it is probable that the irregularity of the feeding of patients with ED does not ensure optimal levels of tryptophan, such as to induce a production of the neurotransmitter sufficient to make the action of the drugs manifest; however, an RCT [21], although conducted in a non-amplimentary sample, showed that nutritional supplementation of amino acids (including also tryptophan) did not lead to symptomatic improvement, nor to greater efficacy of fluoxetine treatment in AN. Kaye [22] also hypothesized that the poor response to $\mathrm{AD}$ in the $\mathrm{AN}$ would be linked to prolonged fasts, which would have an adverse effect on the number of 5HT1a receptors and on the concentration of extracellular serotonin. Some double-blind RTCs have tested the use of fluoxetine in anorexic patients to evaluate their ability to reduce relapses, but with disappointing results [6].

Also the drugs that act on the metabolism of serotonin and noradrenaline (Noradrenergic and Specific Serotonergic Antidepressants, NaSSA) have been used in the AN: a promi-sing case report [23] has revealed that the use of mirtazapine is able to determine a significant recovery weight and improved mood in a patient who had been suffering from AN for many years. The evidence of the literature, as a whole, does not support the use of $\mathrm{AD}$ in the treatment of $\mathrm{AN}$, both in the acute phase and in the maintenance phase.

In contrast, many studies tend to favor the efficacy of various AD drugs (TCA, SSRI, SNRI and monoamine oxidase inhibitors, IMAO) in the treatment of BN, both for their ability to reduce binge eating crises and purging behaviors as for improving mood and anxiety [24 - 28]. Although effective enough, MAOIs and TCAs are not recommended for clinical use due to the frequent and severe adverse events associated with their use. As for SSRIs, various studies have shown not only a good efficacy in reducing the main symptoms of BN but also an excellent tolerability profile; the greatest evidence has accumulated for fluoxetine, citalopram, sertraline and fluvoxamine [2, $24-28]$. Note that, in general, the dose of SSRI used in the treatment of $\mathrm{BN}$ is higher than that usually used in the treatment of depression [6].

Among the SSRIs, fluoxetine was the most studied molecule in patients with $\mathrm{BN}$ and is, to date, the only drug authorized by the US Food and Drug Administration for the treatment of BN (at a dose of $60 \mathrm{mg} /$ day). A large multi-center study compared fluoxetine (at a dose of $60 \mathrm{mg} /$ day) with placebo, confirming the superiority of the drug compared to placebo compared to the reduction of both the binge eating crisis $(67 \% v s .33 \%)$ and the phenomena of purging $(56 \% v s$. $5 \%$ ); lower doses of fluoxetine, on the other hand, were not as effective [29]. BN is a disease whose course is characterized by a tendency to chronic and frequent relapses: therefore, studies on short periods have limited clinical value. Most of the evidence of efficacy is supported, unfortunately, only by studies lasting a few months, also due to the poor compliance with the drugs of these patients [30]. The RTC study with the longer duration of observation (follow-up to 58 weeks) confirmed the efficacy of fluoxetine compared to placebo, not only in reducing episodes of binge/purging behaviors and obsessivecompulsive symptoms but also in reducing the frequency of relapses [31].

Treatment of the $\mathrm{BN}$ with the only $\mathrm{AD}$ available on the market for selectively noradrenergic action, reboxetine, was evaluated in only two uncontrolled studies, although with fairly encouraging results $[32,33]$.

Various AD, both tricyclic and SSRI, have also proved useful in the treatment of Binge Eating Disorder (BED), both with respect to the decrease in the frequency of Binge Eating (BE) and the improvement of depressive and anxious symptoms, often present in the clinical picture of these disorders [34]. A large meta-analysis on the subject, which aggregated data on over 300 patients with BED, showed that SSRI treatment favored a significant reduction in binge eating disorders compared to placebo [35]. Also, another metaanalysis of the same period conducted on seven studies, which examined 335 patients with BED, confirmed that the use of SSRIs was able to induce a significant reduction of binge eating crises, compared to use of placebo. Such meta-analyzes, however, reported a modest effect of SSRIs, when used to control the body weight of patients with DCA [36].

Regarding the "dual-action" AD drugs, that is able to induce a selective inhibition of both serotonin and norepinephrine reuptake, an open and uncontrolled study [37] on the use of venlafaxine in 35 women, obese or in overweight, reported a significant reduction in both binge eating and body weight crises. More recently, a double-blind RTC of 40 patients treated with another dual action $\mathrm{AD}$ (duloxetine, at a mean dose of $78 \mathrm{mg}$ /day), showed sufficient efficacy of duloxetine in reducing the number and frequency of seizures. of binge, as well as body weight and depressive symp-tomatology [38].

For bupropion, an antidepressant with noradrenergic and dopaminergic action, there is some evidence [19] of efficacy in the treatment of both BN and BED, but these are two open studies on small samples; the use of bupropion is however not advisable in these clinical settings, due to the high risk of inducing epileptic seizures.

Some case reports have highlighted the efficacy of agomelatine, an antidepressant agonist of MT1 and MT2 receptors for melatonin and antagonist of 5HT2 serotonergic receptors, in reducing the number and duration of the awakenings, the alimentary and depressive symptoms, assessed with the NEQ and HAM-D scale, in the treatment of the Night Eating Syndrome (NES) [39]. Sibutramine, an anti-obesity agent with a mechanism similar to $\mathrm{AD}$ (inhibition of serotonin and norepinephrine reuptake), has demonstrated in a number of controlled studies a significant efficacy in reducing both binge eating and body weight crises, compared to placebo [40 - 42]. In recent years, however, the frequent onset of cardiovascular adverse events has led to the withdrawal of sibutramine from the market, both in Europe and in the United States. To date, there are no controlled studies in the literature that directly compare the efficacy of various antidepressants, with different mechanisms of action, in the treatment of BN and BED. 


\subsection{Anti-Epileptics}

In recent years, various studies have suggested the use of Anti-Epileptic Drugs (AED) and other mood stabilizers in the management of some forms of ED. There are various reasons for these therapeutic indications. Firstly, AEDs have been found useful in the treatment of various psychiatric conditions associated with ED, such as bipolar disorder, head-ache, anxiety disorders, personality disorders and substance abuse [43 - 48]. Moreover, many AEDs interact with various neurotransmitter systems involved in the regulation of appetite and body weight, in particular glutamatergic, GABAergic, serotonergic, dopaminergic and peptidergic systems [43, 44], with different effects: for example, valproate and pregabalin induces increased appetite and weight gain, while topiramate, zonisamide and phenalbate lead to decreased appetite and decreased weight [18].

In particular, topiramate has been shown to have a broad spectrum of action on ED: it has been proposed both as an antibinge eating and anti-purging agent and to promote weight loss, proving to be potentially useful for the treatment of BN and BED. Two controlled studies reported that the use of topiramate in the treatment of $\mathrm{BN}$ induced a significant reduction in binge and purging behaviors; in the first study, in patients treated with an average topiramate dose of 100 $\mathrm{mg} /$ day, binging and purging crises had decreased by $44.8 \%$ (compared to a $10 \%$ reduction in patients taking placebo) [45]; in the second study [46], topiramate (at a mean dose of 250 $\mathrm{mg} /$ day) induced a significant reduction in the frequency of binge eating episodes, elimination pipelines, body weight and disability detected by the "SF36 Health Survey" scale. Regarding the treatment of BED with this drug, a multicenter, controlled and randomized study, conducted in 407 patients followed for 16 weeks, reported that the use of an average dose of $300 \mathrm{mg}$ /day topiramate-induced a net reduction in the frequency of episodes of bingeing, significant weight loss and improvement of psychiatric comorbidity, particularly with respect to the obsessive-compulsive aspects and impulsivity [47]. The efficacy of topiramate in reducing binge eating crises in patients resistant to other therapeutic approaches and in the forms arising after bariatric therapy has also been reported [48]. Topiramate, however, can induce some relevant adverse events (such as asthenia, impaired mnesic capacities and concentration, to mental confusion) that may sometimes limit their use in clinical practice [48].

Zonisamide, associated with CBT, has been shown to be useful in the treatment of 52 patients with obesity-associated $\mathrm{BED}$, in an open label, one-year study, resulting in reduced binge eating and weight control [49]; zonisamide also has a profile of potentially dangerous adverse events in patients with DCA and its clinical use should be evaluated with caution.

\subsection{Anti-Obesity Drugs}

Orlistat, a gastrointestinal lipase inhibitor, has been proposed to reduce (albeit moderately) binge eating and to promote weight loss in patients with BED. In the study by Golay et al. [50], the use of orlistat (at a dose of $360 \mathrm{mg} /$ day) associated with a moderately hypocaloric diet, induced a weight reduction of $7.4 \%$ (compared to $2.3 \%$ of placebo) in 24 weeks of treatment, but the number of bulimic crises was not significantly lower, compared to placebo.

\subsection{Antagonistic Drugs of 5HT3 Receptors}

Ondansetron is a drug predominantly used in oncology due to its antinausea action during anti-neoplastic chemotherapy and has recently been evaluated for the treatment of vomiting in the BN. The authors of a four-week controlled study of 29 female patients found that ondansetron significantly reduced episodes of binge eating and self-induced vomiting compared to the placebo group [51].

\subsection{Selective Inhibitory Drugs of the Pre-Synaptic Trans- port of Norepinephrine}

Atomoxetine is a selective inhibitor of the norepinephrine pre-synaptic transport mechanism, without direct action on serotonin or dopamine transporters, authorized for the treatment of attention deficit hyperactivity disorder. The drug was evaluated, in a single controlled study compared to placebo, lasting 10 weeks, in 40 patients with BED, at an average dose of $100 \mathrm{mg} /$ day [52]; the authors of the study reported a reduction in the binge eating crises, the sensation of hunger and body weight in the treated group; the most common adverse effects during the study were xerostomia, nausea, insomnia, nervousness, headache and vertigo [52].

\subsection{Hormonal Therapy}

Considering the different hormonal imbalances that often arise in the course of $\mathrm{AN}$, treatment with various opoterapic agents (above all, growth hormone - or growth hormone, GH and testosterone) has been proposed several times, to induce weight recovery in these patients. One of the first controlled studies on the subject [53] evaluated the effect of administration of $15 \mathrm{mg} / \mathrm{kg} /$ day of $\mathrm{GH}$ on 18 adolescents admitted with diagnosis of AN; after a 4-week observation period, the authors found no significant weight gain, but only a more rapid medical stabilization and a significant reduction in hospitalization days compared to the placebo group. More recently, Miller et al. [54] investigated the effects of testosterone use, transdermally administered to 38 women between the ages of 18 and 38; patients treated with testo-sterone had shown, compared to those treated with placebo alone, an improvement in mood, but no significant weight gain.

Hormone replacement therapy with Estrogen-Progestin (EP) for the treatment of amenorrhea in anorexic patients, although intuitively reasonable, does not present any substantial clinical advantage. The same eventuality of depriving haemorrhage, typical of non-continuous progesterone treatment, is not always possible if there is not adequate progestogen preparation of the endometrial mucosa. Furthermore, EP therapy is often experienced by patients as highly intrusive, almost as manipulation of one's own will and body. Finally, the frequent sensation of widespread turgidity and swelling, which often accompanies EP therapy, may accentuate weight and body shape concerns, typical of patients with DCA. Treatment with EP drugs can, therefore, find a rationale for use substantially when associated endocrinological diseases are present (such as polycystic ovarian syndrome, oligo-polymenorrhea, ovarian 
cysts, metrome-noraggie of various etiology, etc.) or when it is necessary to ensure oral contraception to the user. Antiandrogenic drugs have also been used in the treatment of $\mathrm{BN}$. In a controlled study [55], the combination of citalopram (40 $\mathrm{mg} /$ day) and flutamide $(500 \mathrm{mg}$ /day), a testosterone receptor antagonist, resulted in a more effective reduction of seizures in the 46 women studied. binge eating, both with respect to the group taking placebo alone and to the group taking citalopram alone.

\subsection{Stimulants}

Lisdexamfetamine (LDX) is a prodrug of the Central Nervous System (CNS) stimulant dextroamphetamine, a phenethylamine of the amphetamine class that is approved for treatment of children and adults with Attention Deficit Hyperactivity Disorder (ADHD) [56]. LDX influences the edonic system which involves the prefrontal areas, particularly the orbitofrontal cortex and corticostriatal circuits including the nucleus accumbens that play an important role in reward processes and upregulates Cocaine and Amphetamine Regulated Transcript (CART)expression [57].

LDX is the only drug approved by FDA for treatment of moderate to severe BED in adults. In a recent safety and tolerability trial, there was a 4-week initial titration dose which started at $30 \mathrm{mg} / \mathrm{d} \mathrm{LDX}$; the target and maintenance doses were between 50 and $70 \mathrm{mg}$ LDX given over 48 weeks [57].

\subsection{Cannabinoid Receptor Antagonist}

Dronabinol is the stereochemical variant of delta-9-THC, called trans-delta-9-tetrahydrocannabinol, the main psychoactive principle of Cannabis, a pharmacologically active form on the CB1 and CB2 receptors. The drug is registered, since 1985, for the treatment of nausea and vomiting in patients in cancer chemotherapy and for the stimulation of appetite in patients with AIDS-related syndrome and in the forms of cancer-based cachexia [58]. An increase in weight gain compared to placebo [59].

\section{FUTURE PERSPECTIVES AND RESEARCHES}

Several studies on the genetic aspects involved in the genesis of ED suggest that EDs present not only psychiatric but also immune or metabolic aspects and therefore it is reasonable to suppose that there are different subtypes in the different syndromic manifestations of ED [5]. For example, alterations in the inflammatory cytokine system have been reported in patients suffering from ED $[60,61]$ who are actively involved in the regulation of appetite and therefore we could think of the use of molecules able to act on these targets. Moreover, in food-related pathologies, with its imposing dietary alterations, the gastrointestinal microbiome is widely implicated for which probiotics, prebiotics and bioactive nutrients could have considerable therapeutic potential for influencing the regulation of appetite and psychopathology in ED [62]. Therefore it is definitely possible that in the near future we can find other pharmacological targets for the treatment of ED, not only in the central nervous system but also on the immune activity and on the bacteria, fungi and other species that make up and regulate our microbiome.

\section{DISCUSSION}

The treatment of eating disorders is mental health of particular complexity and must, therefore, be framed necessarily in a multidimensional perspective, in which the psychotherapeutic interventions overlap with nutritional rehabilitation and biological treatments. In this sense, pharmacological therapy should be provided within an integrated treatment path, in order not only to promote remission of the core symptoms in the acute phase of the disease but also to prevent relapses over time and to treat frequent psychiatric comorbidity. Unfortunately, ED pharmacotherapy is currently supported by still modest evidence based on a few randomized controlled trials [13]. The available RCTs often show, however, some significant limits. As already noted previously, the number of experimental groups of such studies is often insufficient to draw significant conclusions with respect to their actual clinical impact. Furthermore, no direct comparison studies have been conducted between the different psychotropic drugs in the treatment of ED and this also helps to limit the translational relapse of the data currently available in the literature on the subject. Equally small are also the controlled studies that evaluate the association between psychotherapies and drugs and those that can clarify which are the most appropriate augmentation and combination strategies, among different pharmacological agents in the treatment of ED (Tables 1-3).

In particular, the problem of insufficient duration of follow-up observations (often in the studies the subjects are assessed for a few weeks or a few months, while very rarely for more than a year) is particularly cogent in the case of ED: these morbid conditions, In fact, they often tend to a chronic course and a substantial lack of information regarding medium-long observation times does not allow clinicians to adequately and realistically evaluate the implications of these studies for pharmacological treatment for ED, in routine conditions [6].

Another element of high criticality in the evaluation of the effectiveness of pharmacological treatments for ED lies in the high number of "drop-outs" reported in the studies. A possible explanation for the low compliance to long-term treatment in these patients may be related to the experiences that the subjects with ED, and in particular the patients with AN, often experience in terms of intrusiveness, aggression and uncontrollability during the intake of treatments pharmacological. Furthermore, the possible side effects of the drugs (in particular, the weight gain caused by many of them) and the frequent organic comorbidities can negatively affect long-term compliance to drug treatment [14].

A further problem of the studies examined resides in the heterogeneity of the measures used in the various studies as outcome indicators: the ED are pathologies in themselves very heterogeneous with respect to the course and the clinical characteristics, which often pose to the clinician many problems concerning the individuation clear and unambiguous indicators of response to psychopharmacological therapies; the presence also in literature of measures often very different in the empirical studies could contribute to increase the heterogeneity of the available evidence and limit the possibility, for the clinician, to orientate more safely between the therapeutic opportunities for specific diagnostic subgroups. Finally, a fur- 
ther element that can contribute to creating a distance between the results of the controlled studies and the clinical reality of the psychopharmacological treatment of EDs is represented by the lack of a clear standardization of the dosage of these drugs to be used in the various EDs; in most of the RCTs existing in the literature, there is, in fact, a wide poso-logical variability, even with respect to the same pathological condition $[6,13$, 14]. Clearly, the variability of the organic conditions, the sensitivity to drugs and the different expression of their possible side effects in the individual subjects with ED, tends not to favor this standardization (often, for example, it is necessary to use lower dosages in patients with severe organic compromise or particularly sensitive to the effects of drugs). Moreover, even malnutrition (especially through hypoproteinemia and hypoalbuminemia, which reduce the blood transport of the drugs themselves) can induce significant changes in the pharmacokinetic and pharmacodynamic characteristics of the various pharmacological agents, which in turn

\section{Table 1. AN Pharmacotherapy - General Considerations.}

\begin{tabular}{|c|}
\hline $\begin{array}{c}\text { Anorexic patients experience pharmacological intervention as an invasive, } \\
\text { uncontrollable action as a strong, toxic and aggressive treatment. }\end{array}$ \\
\hline Resistance to undertaking a cure is one of the most marked pathological traits in AN. \\
\hline The AN therapy consists in setting up simultaneous or sequential interventions of individual and / or family psychotherapy, \\
nutritional and pharmacological,being the symptoms of the disease multiplied by biological, \\
psychological and family factors.
\end{tabular}

Table 2. BN Pharmacotherapy

\begin{tabular}{|c|}
\hline \\
\hline Tricyclic antidepressants with precaution for the marked side effects \\
\hline$\checkmark$ SNRI (venlafaxine) \\
\hline Short-term treatment seems able to reduce by $70 \%$ the frequency of binge eating and elimination behavior, as well as improving the emotional \\
component. \\
\hline$\bullet$ Fluoxetine, $60 \mathrm{mg} /$ day is the drug of choice: there is good evidence of efficacy, the side effects profile is modest and the only drug approved by \\
the FDA for Bulimia Nervosa. \\
\hline$\bullet$ The minimum duration of an effective treatment should be no less than six months. \\
\hline
\end{tabular}

Table 3. BED Pharmacotherapy

\begin{tabular}{|c|}
\hline \\
\hline In the BED a therapeutic strategy is indicated in which the initial use of drug therapy, to initiate weight loss and reduce binge crises, then follows a \\
psychotherapy (cognitive-behavioral type) aimed at acting on the psychological factors involved in the etiopathogenesis of the disorder.
\end{tabular}

Table 4. Summarizes these therapies with their effect (good/moderate/poor) on the 3 eating disorders: AN, BN, BED and include side-effects.

\begin{tabular}{|c|}
\hline ANOREXIA NERVOSA \\
\hline Therapies Effect Side effects \\
\hline SGA (olanzapine) moderate sedation, hyperglycemia \\
\hline SGA (aripiprazole) moderate vertigo, akathisia \\
\hline
\end{tabular}




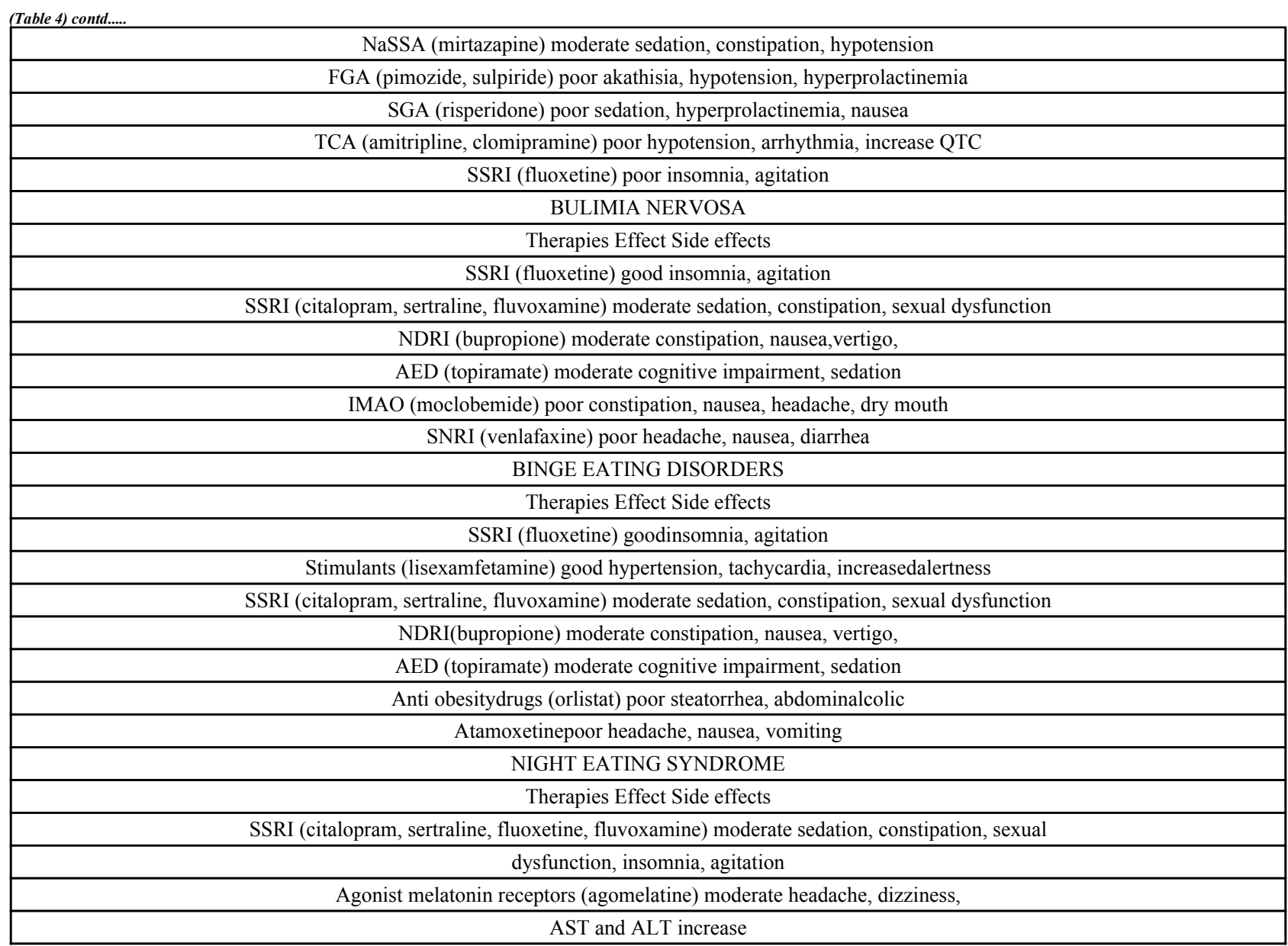

Note: FGA: First Generation Antipsychotics; SGA:Second Generation Antipsychotics; NaSSA: Noradrenergic specific serotoninergic antidepressant; TCA: Tryciclic antidepressant; SSRI: Selective serotonin reuptake inhibitors; NDRI: Noradrenergic dopaminergic reuptake inhibitors; AED:Anti-epilepticdrugs; SNRI: Serotonin Noradrenergic reuptake inhibitors; IMAO: Inhibitors monoamine oxidase;

further contribute to determine a discrepancy in the dosing guidelines in this clinical setting $[6,13,14]$.

Despite the limitations listed above, the available scientific evidence relating to pharmacotherapy seems to reveal that it may potentially play an important role in the management of EDs. Although in fact, with the exception of fluoxetine for the treatment of $\mathrm{BN}$, no drug has been officially authorized for therapeutic use in ED, the use of psychotropic drugs for the treatment of ED has steadily increased over the years. A recent retrospective study [63] evaluating the clinical management of $\mathrm{AN}$ in 520 women reported that the EMS prescription for the AN rose from $8.9 \%$ in the period $1999-2002$ to $18.5 \%$, in the period 2003-2009, and at the time of detection to over $50 \%$ of patients had been prescribed psychopharmacological therapy (48\% with antidepressant drugs and $13 \%$ with antipsychotics) $[20,30]$.

Although the use of psychotropic drugs in ED should be considered essentially an off-label practice (which should, therefore, be implemented under the direct responsibility of the doctor, with informed consent from the patient or his parents, if underage), current empirical evidence on psychopharmacotherapy of the EDs allow to formulate cautious suggestions regarding its implementation in clinical practice [30].

The use of SSRIs, in particular of high dose fluoxetine, in the treatment of BN, allows to reduce the episodes of binge and purging and binge crises in patients with BED, in the short term. Also for topiramate, there is good evidence of effectiveness in reducing the frequency and the amount of binge episodes with weight reduction, both in the BN and in the BED therapy. To date, the data supporting the use of low doses of second-generation antipsychotics (except that, partially, for olanzapine) in an attempt to reduce the polarized ideation on weight and body shapes, the obsessive components, are modest. and anxious in anorexic patients [18].

Moreover, although the controlled studies are still few and with various methodological limitations, antidepressants seem to have a slightly more useful role than other drugs in the childhood and adolescent forms of ED, especially when the subject has other psychiatric manifestations in comorbidity (especially depression)., while atypical antipsychotics play an even more limited role than in adult forms [18].

Table 4 summarizes the described therapies with their effect (good/moderate/poor) on the 3 eating disorders: AN, BN, BED and include possible side-effects 


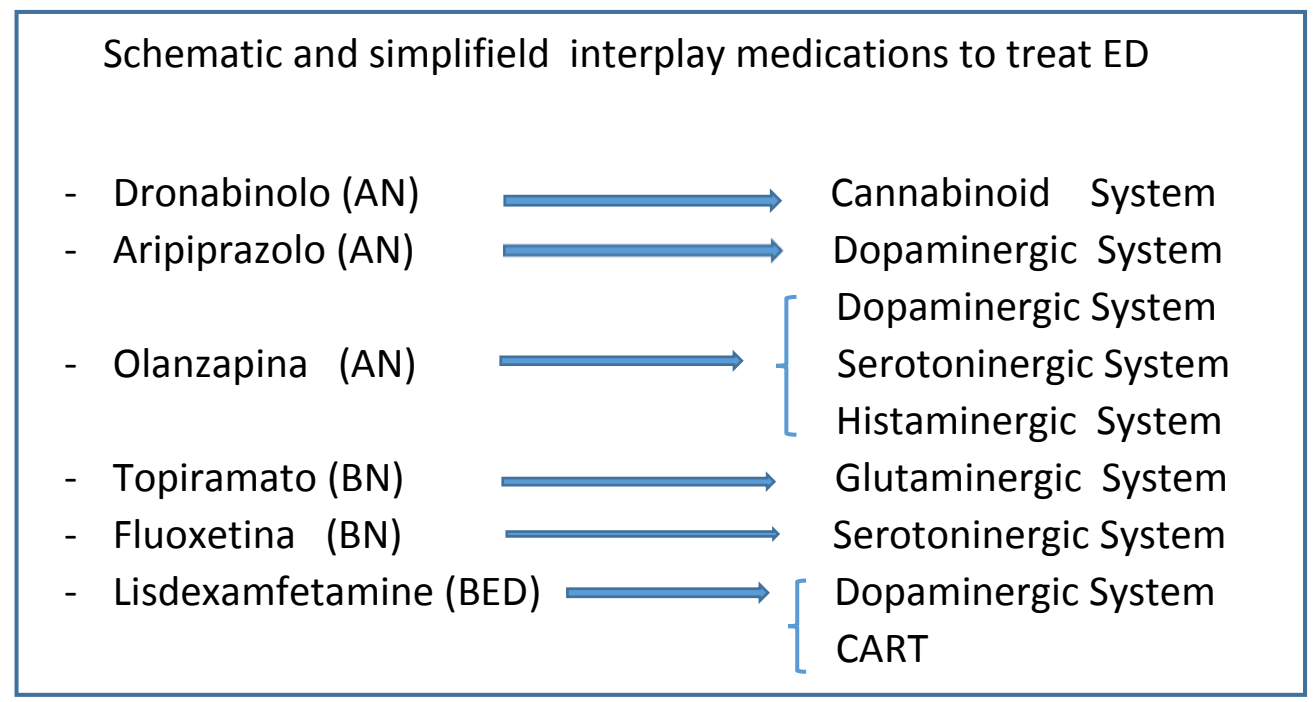

Fig. (1). Schematic and simplifield interplay medications to treat ED.

\section{CONCLUSION}

Pharmacotherapy is already a non-negligible therapeutic alternative in patients who do not respond in an inadequate way to psychotherapies, in severe forms where malnutrition or frequent binge/purging crises limit or prevent the psychotherapeutic approach altogether, again, when there are significant psychiatric comorbidities (such as mood disorders, anxiety disorders, insomnia, marked obsessive-compulsive symptoms, personality and behavioral disorders) [64 - 66]. Psychotropic drugs, while not yet playing a significant role, decisive or sufficient in the treatment of ED, can be a valuable aid in clinical practice and some experimental studies have shown its usefulness, at least in some cases. Despite the methodological limitations of studies carried out over the last few decades, research into drug therapy for EDs has made significant progress $[2,3,63]$.To fully answer the question regarding the real usefulness of pharmacotherapy for EDs, however, it will be necessary for studies in the coming years to be conducted with longer longitudinal evaluations, with better defined outcome indicators (for example, not related only to body weight, but also to eating behaviors and cognitive profiles), in sufficiently large samples and representative of the so called "real world" (or even those patients with serious conditions of malnutrition and / or psychiatric and medical comorbidities). Only on the basis of solid empirical evidence will it be possible to consider the optimal objective $[64,65]$ to design for each patient with ED, a truly individualized and integrated therapeutic program, which combines the most effective pharmacological therapy with the most appropriate psychotherapeutic treatment, depending of indicators both "diagnostic" (that is, related to the type of pathology) and "clinical" (that is, related to the individual characteristics of the patient) (Fig. 1).

\section{CONSENT FOR PUBLICATION}

Not applicable.

\section{CONFLICT OF INTEREST}

The authors declare no conflict of interest, financial or otherwise.

\section{ACKNOWLEDGEMENTS}

Declared none.

\section{REFERENCES}

[1] Treasure J, Claudino AM, Zucker N. Eating disorders. Lancet 2010; 375(9714): 583-93. [http://dx.doi.org/10.1016/S0140-6736(09)61748-7] [PMID: 1993 1176]

[2] Flament MF, Bissada H, Spettigue W. Evidence-based pharmacotherapy of eating disorders. Int J Neuropsychopharmacol 2012; 15(2): 189-207.

[http://dx.doi.org/10.1017/S1461145711000381] [PMID: 21414249]

[3] National Institute for Clinic Excellence (NICE). Eating disorders: Core interventions in the treatment and management of anorexia nervosa, bulimis nervosa and related disorders. Clinical guideline Number 9. London 2004.

[4] American Psychiatric Association. Practice guidelines for the treatment of patients with eating disorders.Practice guidelines for the treatment of psychiatric disorders. 3rd ed. 2006.

[5] Aigner M, Treasure J, Kaye W, Kasper S. World Federation of Societies of Biological Psychiatry (WFSBP) guidelines for the pharmacological treatment of eating disorders. World J Biol Psychiatry 2011; 12(6): 400-43.

[http://dx.doi.org/10.3109/15622975.2011.602720] [PMID: 21961502]

[6] Hay PJ. Clinical psychopharmacology of eating disorder: A research update. Int J Neuropsychopharm 2012; 6: 1-14.

[7] Powers PS, Santana C. Available pharmacological treatments for anorexia nervosa. Expert Opin Pharmacother 2004; 5(11): 2287-92. [http://dx.doi.org/10.1517/14656566.5.11.2287] [PMID: 15500375]

[8] Vandereycken W, Pierloot R. Pimozide combined with behavior therapy in the short-term treatment of anorexia nervosa. A doubleblind placebo-controlled cross-over study. Acta Psychiatr Scand 1982; 66(6): 445-50.

[http://dx.doi.org/10.1111/j.1600-0447.1982.tb04501.x] [PMID: 6758 492]

[9] Vandereycken W. Neuroleptics in the short-term treatment of anorexia nervosa. A double-blind placebo-controlled study with sulpiride. Br J Psychiatry $1984 ; 144: 288-92$.

[http://dx.doi.org/10.1192/bjp.144.3.288] [PMID: 6367876]

[10] Mondraty N, Birmingham CL, Touyz S, Sundakov V, Chapman L, Beumont P. Randomized controlled trial of olanzapine in the treatment of cognitions in anorexia nervosa. Australas Psychiatry 2005; 13(1): $72-5$.

[http://dx.doi.org/10.1080/j.1440-1665.2004.02154.x] [PMID: 1577 7417]

[11] Brambilla F, Garcia CS, Fassino S, et al. Olanzapine therapy in anorexia nervosa: Psychobiological effects. Int Clin Psychopharmacol 
2007; 22(4): 197-204.

[http://dx.doi.org/10.1097/YIC.0b013e328080ca31] [PMID: 1751 9642]

[12] Bissada H, Tasca GA, Barber AM, et al. Olanzapine in the treatment of low body weight and obsessive thinking in women with anorexia nervosa : A randomized, double-blind, placebo-controlled trial. Am J Psychiatry 2008; $165: 1227-8$.

[http://dx.doi.org/10.1176/appi.ajp.2008.07121900]

[13] Powers PS. Pharmacotherapy for eating disorders and obesity child adolescs psychiatric. Clin N Am 2009; 18: 175-87.

[14] Himmerich H, Treasure J. Psychopharmacological advances in eating disorders. Expert Rev Clin Pharmacol 2018; 11(1): 95-108. [http://dx.doi.org/10.1080/17512433.2018.1383895] [PMID: 2893 3969]

[15] Guido KW. Aripiprazole, a partial dopamine agonist to improveadolescentanorexia nervosa A case series. Int J Eat Disor 2015; 49(5): 529-33.

[16] Trunko ME, Schwartz TA, Duvvuri V, Kaye WH. Aripiprazole in anorexia nervosa and low-weight bulimia nervosa: Case reports. Int J Eat Disord 2011; 44(3): 269-75.

[http://dx.doi.org/10.1002/eat.20807] [PMID: 20186719]

[17] Hagman J, Gralla J, Sigel E, et al. A double-blind, placebo-controlled study of risperidone for the treatment of adolescents and young adults with anorexia nervosa: A pilot study. J Am Acad Child Adolesc Psychiatry 2011; 50(9): 915-24.

[http://dx.doi.org/10.1016/j.jaac.2011.06.009] [PMID: 21871373]

[18] McElroy SL, Guerdjikova AI, Mori N, O'Melia AM. Current pharmacotherapy options for bulimia nervosa and binge eating disorder. Expert Opin Pharmacother 2012; 13(14): 2015-26. [http://dx.doi.org/10.1517/14656566.2012.721781] [PMID: 22946772]

[19] Mischoulon D, Eddy KT, Keshaviah A, et al. Depression and eating disorders: Treatment and course. J Affect Disord 2011; 130(3): 470-7. [http://dx.doi.org/10.1016/j.jad.2010.10.043] [PMID: 21109307]

[20] Claudino AM, Hay P, Lima MS, Bacaltchuk J, Schmidt U, Treasure J. Antidepressants for anorexia nervosa. Cochrane Database Syst Rev 2006; (1): CD004365. [PMID: 16437485]

[21] Barbarich NC, McConaha CW, Halmi KA, et al. Use of nutritional supplements to increase the efficacy of fluoxetine in the treatment of anorexia nervosa. Int J Eat Disord 2004; 35(1): 10-5.

[http://dx.doi.org/10.1002/eat.10235] [PMID: 14705152]

[22] Kaye WH. Neurobiology of anorexia nervosa purdueingestivebehavior research center symposium influences on eating and body weight over the lifespan Child. Adol Psysiol Behav 2008; 35: 121-35.

[23] Safer DL, Darcy AM, Lock J. Use of mirtazapine in an adult with refractory anorexia nervosa and comorbid depression: A case report. Int J Eat Disord 2011; 44(2): 178-81. [PMID: 20127940]

[24] Bacaltchuck J, Hay J. Antidepressants vs placebo for people with bulimia nervosa. Cochrane Database Syst Rev 2003; (1): CD003391.

[25] Hay PJ, Claudino AC. Bulimia Nervosa. Clinical Evidence Review Update 2010; (7): 1009.

[26] Milano W, Petrella C, Sabatino C, Capasso A. Treatment of bulimia nervosa with sertraline: A randomized controlled trial. Adv Ther 2004; 21(4): 232-7.

[http://dx.doi.org/10.1007/BF02850155] [PMID: 15605617]

[27] Milano W, Siano C, Putrella C, Capasso A, Capasso A. Treatment of bulimia nervosa with fluvoxamine: a randomized controlled trial. Adv Ther 2005; 22(3): 278-83. a

\section{[http://dx.doi.org/10.1007/BF02849936] [PMID: 16236688]}

[28] Milano W, Petrella C, Capasso A. Treatment of bulimia nervosa with citalopram: A randomized controlled trial. Biomed Res 2005; 16: 85-7. c

[29] Fluoxetine Bulimia Nervosa Collaborative Study Group. Fluoxetine in the treatment of bulimia nervosa. A multicenter, placebo-controlled, double-blind trial. Arch Gen Psychiatry 1992; 49(2): 139-47.

[http://dx.doi.org/10.1001/archpsyc.1992.01820020059008] [PMID: 1550466]

[30] Martiadis V, Castaldo E, Monteleone P, Maj M. The role of psychopharmacotherapy in the management of eating disorders. Clin Neuropsychiatry 2007; 4(2): 51-60

[31] Romano SJ, Halmi KA, Sarkar NP, Koke SC, Lee JS. A placebocontrolled study of fluoxetine in continued treatment of bulimia nervosa after successful acute fluoxetine treatment. Am J Psychiatry 2002; 159(1): 96-102.

[http://dx.doi.org/10.1176/appi.ajp.159.1.96] [PMID: 11772696]

[32] El-Giamal N, de Zwaan M, Bailer U, et al. Reboxetine in the treatment of bulimia nervosa:a report of seven cases. Int clin Psychophar 2000; 15: 111-5.

[33] Fassino S, Daga GA, Boggio S, Garzaro L, Pierò A. Use of reboxetine in bulimia nervosa: A pilot study. J Psychopharmacol (Oxford) 2004; 18(3): 423-8.

[http://dx.doi.org/10.1177/026988110401800314] [PMID: 15358988]

[34] Reas D1, Grilo CM. Current and emerging drug treatments for binge eating disorder. Expert OpinEmerg Drug 2014; 19(1): 99-142.

[35] Stefano SC, Bacaltchuk J, Blay SL, Appolinário JC. Antidepressants in short-term treatment of binge eating disorder: Systematic review and meta-analysis. Eat Behav 2008; 9(2): 129-36.

[http://dx.doi.org/10.1016/j.eatbeh.2007.03.006] [PMID: 18329590]

[36] Reas DL, Grilo CM. Review and meta-analysis of pharmacotherapy for binge eating disorder. Obesity (Silver Spring) 2008; 16(9): 2024-38.

[http://dx.doi.org/10.1038/oby.2008.333] [PMID: 19186327]

[37] Malhotra S, King KH, Welge JA, Brusman-Lovins L, McElroy SL. Venlafaxine treatment of binge-eating disorder associated with obesity: A series of 35 patients. J Clin Psychiatry 2002; 63(9): 802-6. [http://dx.doi.org/10.4088/JCP.v63n0909] [PMID: 12363121]

[38] Guerdjikova AI, McElroy SL, Winstanley EL, et al. Duloxetine in the treatment of binge eating disorder with depressive disorders: A placebo-controlled trial. Int J Eat Disord 2012; 45(2): 281-9. [http://dx.doi.org/10.1002/eat.20946] [PMID: 21744377]

[39] Milano W, De Rosa M, Milano L, Riccio A, Sanseverino B, Capasso A. Successful treatment with agomelatine in NES:A series five cases. Open Neurol J 2013; 7: 32-7.

[http://dx.doi.org/10.2174/1874205X20130626001] [PMID: 2413 3551]

[40] Appolinario JC, Bacaltchuk J, Sichieri R, et al. A randomized, doubleblind, placebo-controlled study of sibutramine in the treatment of binge eating disorder. Arch Gen Psychiatry 2003; 60(11): 1109-16. [http://dx.doi.org/10.1001/archpsyc.60.11.1109] [PMID: 14609886]

[41] Milano W, Petrella C, Casella A, Capasso A, Carrino S, Milano L. Use of sibutramine, an inhibitor of the reuptake of serotonin and noradrenaline, in the treatment of binge eating disorder: A placebocontrolled study. Adv Ther 2005; 22(1): 25-31. b

[http://dx.doi.org/10.1007/BF02850181] [PMID: 15943219]

[42] Wilfley DE, Crow SJ, Hudson JI, et al. Efficacy of sibutramine for the treatment of binge eating disorder: a randomized multicenter placebocontrolled double-blind study. Am J Psychiatry 2008; 165(1): 51-8. [http://dx.doi.org/10.1176/appi.ajp.2007.06121970] [PMID: 1805 6225]

[43] Meister B. Neurotransmitters in key neurons of the hypothalamus that regulate feeding behavior and body weight. Physiol Behav 2007; 92(1-2): 263-71.

[http://dx.doi.org/10.1016/j.physbeh.2007.05.021] [PMID: 17586536]

[44] Gao Q, Horvath TL. Neuronal control of energy homeostasis. FEBS Lett 2008; 582(1): 132-41.

[http://dx.doi.org/10.1016/j.febslet.2007.11.063] [PMID: 18061579]

[45] Hedges DW, Reimherr FW, Hoopes SP, et al. Treatment of bulimia nervosa with topiramate in a randomized, double-blind, placebocontrolled trial, part 2: Improvement in psychiatric measures. J Clin Psychiatry 2003; 64(12): 1449-54.

[http://dx.doi.org/10.4088/JCP.v64n1208] [PMID: 14728106]

[46] Nickel C, Tritt K, Muehlbacher M, et al. Topiramate treatment in bulimia nervosa patients: A randomized, double-blind, placebocontrolled trial. Int J Eat Disord 2005; 38(4): 295-300. [http://dx.doi.org/10.1002/eat.20202] [PMID: 16231337]

[47] McElroy SL, Hudson JI, et al. Topiramato for treatment of binge eating disorder associated ad obesity: a placebo. Biol Psychiatry 2007; 61: 1039-48. a

[http://dx.doi.org/10.1016/j.biopsych.2006.08.008] [PMID: 17258690]

[48] McElroy SL, Guerdjikova AI, Martens B, Keck PE Jr, Pope HG, Hudson JI. Role of antiepileptic drugs in the management of eating disorders. CNS Drugs 2009; 23(2): 139-56.

[http://dx.doi.org/10.2165/00023210-200923020-00004] [PMID: 1917 3373]

[49] Ricca V, Castellini G, Lo Sauro C, Rotella CM, Faravelli C. Zonisamidecombinated with cognitive-behaviour therapy in binge eating disorder: one -year follow-up study. Psychiatry (Edgmont Pa) 2009; 6(11): 23-8.

[PMID: 20049147]

[50] Golay A, Laurent-Jaccard A, Habicht F, et al. Effect of orlistat in obese patients with binge eating disorder. Obes Res 2005; 13(10): 1701-8.

[http://dx.doi.org/10.1038/oby.2005.208] [PMID: 16286517] 
[51] Faris PL, Kim SW, Meller WH, et al. Effect of decreasing afferent vagal activity with ondansetron on symptoms of bulimia nervosa: A randomised, double-blind trial. Lancet 2000; 355(9206): 792-7. [http://dx.doi.org/10.1016/S0140-6736(99)09062-5] [PMID: 107119 27]

[52] McElroy SL, Guerdjikova A, Kotwal R, et al. Atomoxetine in the treatment of binge eating disorder: A randomized placebo-controlled trial. J Clin Psychiatry 2007; 68(3): 390-8. b [http://dx.doi.org/10.4088/JCP.v68n0306] [PMID: 17388708]

[53] Hill K, Bucuvalas J, McClain C, et al. Pilot study of growth hormone administration during the refeeding of malnourished anorexia nervosa patients. J Child Adolesc Psychopharmacol 2000; 10(1): 3-8 [http://dx.doi.org/10.1089/cap.2000.10.3] [PMID: 10755576]

[54] Miller KK, Grieco KA, Klibanski A. Testosterone administration in women with anorexia nervosa. J Clin Endocrinol Metab 2005; 90(3): 1428-33.

[http://dx.doi.org/10.1210/jc.2004-1181] [PMID: 15613421]

[55] Sundblad C, Landén M, Eriksson T, Bergman L, Eriksson E. Effects of the androgen antagonist flutamide and the serotonin reuptake inhibitor citalopram in bulimia nervosa: A placebo-controlled pilot study. J Clin Psychopharmacol 2005; 25(1): 85-8.

[http://dx.doi.org/10.1097/01.jcp.0000150222.31007.a9] [PMID: 1564 3104]

[56] Stahl SM. Lisdexamfetamine. Prescriber's guide: stahl's essential psychopharmacology. $6^{\text {th }}$ ed. Cambridge, United Kingdom: Cambridge University Press 2017; pp. 379-84.

[57] Gasior M, Hudson J, Quintero J, Ferreira-Cornwell MC, Radewonuk J, McElroy SL. Multicenter, open-label, 12 month extension safety and tolerability trial of lisdexamphetaminedismelate in adults with binge eatinf disorder. J Clin Psychopharmacol 2017; 37(3): 315-22.

[http://dx.doi.org/10.1097/JCP.0000000000000702] [PMID: 2838 3364]

[58] Badowski ME, Perez SE. Clinical utility of dronabinol in the treatment of weight loss associated with HIV and AIDS. HIV AIDS (Auckl) 2016; 8: 37-45.

[http://dx.doi.org/10.2147/HIV.S81420] [PMID: 26929669]

[59] Andries A, Frystyk J, Flyvbjerg A, Støving RK. Dronabinol in severe, enduring anorexia nervosa: a randomized controlled trial. Int J Eat Disord 2014; 47(1): 18-23.

[http://dx.doi.org/10.1002/eat.22173] [PMID: 24105610]

[60] Solmi M, Veronese N, Favaro A, et al. Inflammatory cytokines and anorexia nervosa: A meta-analysis of cross-sectional and longitudinal studies. Psychoneuroendocrinology 2015; 51: 237-52.

[http://dx.doi.org/10.1016/j.psyneuen.2014.09.031] [PMID: 25462897]

[61] Pisetsky DS, Trace SE, Brownley KA, et al. The expression of cytokines and chemokines in the blood of patients with severe weight loss from anorexia nervosa: An exploratory study. Cytokine 2014; 69: $110-5$.

[http://dx.doi.org/10.1016/j.cyto.2014.05.018] [PMID: 25022969]

[62] Carr J, Kleiman SC, Bulik CM, Bulik-Sullivan EC, Carroll IM. Can attention to the intestinal microbiota improve understanding and treatment of anorexia nervosa? Expert Rev Gastroenterol Hepatol 2016; 10(5): 565-9.

[http://dx.doi.org/10.1586/17474124.2016.1166953] [PMID: 2700 3627]

[63] Fazeli PK, Calder GL, Miller KK, et al. Psychotropic medication use in anorexia nervosa between 1997 and 2009. Int J Eat Disord 2012; 45(8): 970-6.

[http://dx.doi.org/10.1002/eat.22037] [PMID: 22733643]

[64] Cuzzolaro M. Il trattamento dei Disturbi del Comportamento Alimentare. Noos 2003; 1: 49-66.2003;

[65] Hay P, Chinn D, Forbes D, et al. Royal Australian and New Zealand College of Psychiatrists clinical practice guidelines for the treatment of eating disorders. Aust N Z J Psychiatry 2014; 48(11): 977-1008. [http://dx.doi.org/10.1177/0004867414555814] [PMID: 25351912]

[66] Milano W, Capasso A. Food behavior as risk factor for developing eating disorders. Integrative Food. Nutr Metab (Lond) 2017; 4(6): 1-9.

(C) 2019 Milano and Capasso.

This is an open access article distributed under the terms of the Creative Commons Attribution 4.0 International Public License (CC-BY 4.0), a copy of which is available at: https://creativecommons.org/licenses/by/4.0/legalcode. This license permits unrestricted use, distribution, and reproduction in any medium, provided the original author and source are credited. 